\title{
El pintor Francisco Agustín Grande y el obispo don Antonio Caballero y Góngora. La Piedad del retablo del sagrario de la parroquia de San Miguel, Córdoba (1795)*
}

\author{
Miguel Ángel Nieto Márquez \\ Universidad de Sevilla \\ mamnm91@gmail.com
}

RESUMEN: A finales del siglo XVIII, el obispo ilustrado D. Antonio Caballero y Góngora fundó en Córdoba la Escuela de Bellas Artes, que fue dirigida por el pintor académico Francisco Agustín Grande. El presente artículo pone de relieve el apoyo que el pintor recibió del prelado, interesado en la difusión del gusto academicista, siendo prueba de ello el lienzo de La Piedad de la capilla sacramental de la parroquia de San Miguel.

PALABRAS CLAVE: Academia; Patrocinio artístico; Pintura; Iconografía; Renovación artística.

\section{The Painter Francisco Agustín Grande and the Bishop Antonio Caballero y Góngora. La Piedad in the Sanctuary of the Parish Church of San Miguel, Córdoba (1795)}

\begin{abstract}
At the end of the $18^{\text {th }}$ century, the enlightened bishop, the Right Reverend Antonio Caballero y Góngora founded the School of Fine Arts in Córdoba, which was directed by the academic painter Francisco Agustín Grande. This article highlights the support that the painter received from the prelate, interested in the dissemination of academic taste. The painting La Piedad from the sacramental chapel of the parish of San Miguel is proof of this.
\end{abstract}

KEYWORDS: Academy; Artistic Sponsorship; Painting; Iconography; Artistic Renewal.

Recibido: 17 de diciembre de 2019 / Aceptado: 5 de mayo de 2020

Durante el último tercio del siglo XVIII, las élites sociales cordobesas experimentaron un cambio en su gusto artístico. Buena parte del clero y la nobleza, siguiendo los dictados de la Real Academia de San Fernando, apostó por la recuperación de los cánones clásicos, mientras pervivían en la mayor parte de la sociedad las fórmulas del Barroco, por lo que en un primer momento convivieron en la ciudad, al igual que en resto de España, dos tendencias culturales y artísticas, el Barroco y el Academicismo'.

Tras la muerte del obispo D. Baltasar de Yusta y Navarro el 3 de diciembre de 1787, el rey Carlos III, por Real Orden firmada en Aranjuez el 8 de abril del año siguiente, presentó a Antonio Caballero y Góngora para ocupar la silla episcopal cordobesa, siendo conocedor de sus méritos como arzobispo y virrey de Nueva Granada (Rey, 1989: 53). Este prelado ha pasado a la historia de la ciudad por ser el más fiel seguidor de las ideas de la llustración y por su afición a las artes, hasta el punto de crear un museo y de proteger a artistas, como su paisano José Álvarez Cubero. No obstante, el principal testimonio de su condición de hombre ilustrado fue la creación de una Escuela de Bellas Artes en la ciudad, siguiendo los parámetros de la citada Real Academia de Madrid (Rivas, 1986: 45).

Cómo citar este artículo: NIETO MÁRQUEZ, Miguel Ángel, «El pintor Francisco Agustín Grande y el obispo don Antonio Caballero y Góngora. La Piedad del retablo del sagrario de la parroquia de San Miguel, Córdoba (1795)», Boletín de Arte-UMA, n. ${ }^{\circ}$ 41, Departamento de Historia del Arte, Universidad de Málaga, 2020, pp. 161-169, ISSN: 0211-8483, e-ISSN: 2695-415X, DOI: http://dx.doi.org/10.24310/BoLArte.2020.v41i.7458 
Prieguense de nacimiento, se formó en Granada, licenciándose en teología el 3 de julio de 1744 en el Colegio Imperial de Santa Catalina. Tras opositar a la Canonjía Lectoral de Cádiz en 1745 y ordenarse presbítero en 1750, llegó a ser capellán de la Capilla Real granadina, y canónigo lectoral de Córdoba en 1753. Sus méritos en Hispanoamérica comenzaron en 1775, año en que fue elegido obispo de Chiapas, si bien pasó a ocupar la silla episcopal de Mérida (Yucatán) en septiembre del mismo año, tras haber quedado vacante. En 1777 fue nombrado arzobispo de Santafé de Bogotá, llegando a ocupar también los cargos de gobernador, virrey, capitán general, y presidente de la Audiencia de Nueva Granada. A través del inventario de sus bienes realizado el mismo año, se puede advertir su condición ilustrada, pues poseía 38 cajas de libros, un enorme monetario que contenía monedas españolas y romanas, y por supuesto, una pinacoteca personal con obras de 14 pintores entre los que se encontraban Murillo, Alonso Cano o Juan Carreño entre otros ${ }^{2}$. Su sobresaliente obra cultural también es una clara muestra de su carácter ilustrado, fundando en 1783 la Real Expedición Botánica siguiendo los consejos de José Celestino Mutis, un semillero para la formación de científicos criollos, y mostrando un gran interés por la copia de vocabularios de las lenguas indígenas neogranadinas y la confección de catecismos y confesionarios. En este sentido, Carlos III pidió a las autoridades americanas que remitieran vocabularios de las lenguas de los naturales de cada región, para así colaborar con Catalina de Rusia en el proyecto de elaborar un vocabulario comparativo de las lenguas del mundo. Antonio Caballero y Góngora encargaría esta labor al citado José Celestino Mutis, quien recopiló 21 manuscritos de lenguas indígenas del virreinato ${ }^{3}$. Fue también durante el gobierno de Caballero cuando surgió el periodismo en el territorio neogranadino, con la publicación de Aviso de Terremoto y de La Gaceta de Santafé de Bogotá (Pita, 2016), comenzando también a funcionar el Colegio de Enseñanza para la formación femenina y proyectándose en 1787 el Plan de Universidad y Estudios generales de la ciudad de Santafé con el objetivo de crear una universidad pública, si bien finalmente no se cumplió el objetivo. Durante su gobierno también cabe destacar la fundación de la Sociedad Económica de Amigos del País de Mompós, que funcionaría desde el 12 de septiembre de $1784^{4}$.

En 1788, tras solicitar por segunda vez su renuncia al doble cargo de arzobispo-virrey, Antonio Caballero y Góngo- ra lograría regresar a Córdoba, ocupando su lugar D. Francisco Gil y Lemus (Gómez, 1989: 75). Ya en España, tomó posesión de su nuevo cargo el 27 de enero de 1789 (Rey, 1989: 54), sumándose de inmediato al movimiento ilustrado de la capital cordobesa, que había dado lugar a distintas instituciones como la Real Sociedad Económica Cordobesa de Amigos del País, creada en 1779 bajo el título de Real Sociedad Patriótica (Aranda, 1984: 297-313). Durante el gobierno del nuevo prelado, quien por su condición ilustrada debía considerar que la educación era la medicina para todos los males del país (Aranda, 1989: 8), el deán D. Francisco Xavier Fernández de Córdoba fundó las escuelas gratuitas en los locales que pertenecieron a la extinguida Compañía de Jesús y en un edificio del Pozanco, en el barrio de San Lorenzo.

Desde el punto de vista artístico, el obispo Caballero también patrocinó la Escuela de Bellas Artes, que funcionó durante cinco años hasta su muerte en 1796, de la que poco se conoce acerca de la dirección de sus estudios y métodos (Ortiz, 1984: 23-24). Gracias a un inventario del Archivo General del Obispado de Córdoba, se sabe que fue el mismo prelado quien costeó dibujos, estampas, estatuas, libros y otros utensilios para la escuela. En un segundo inventario realizado en junio de 1796 se incluye una valoración del material y del mobiliario, interviniendo como perito el pintor Francisco Agustín Grande, autor del cuadro que aquí se da a conocer (Aranda, 1989: 7-8). Para la escuela, Caballero alquiló una casa cercana a su residencia, junto al Seminario de San Pelagio, que contaba con cuatro habitaciones en su piso superior y varias estancias en la planta baja donde residían los becarios, además del comedor y la cocina (Aranda, 1988: 37-39). Para difundir los postulados estéticos academicistas, el obispo Caballero hizo venir a Córdoba a tres individuos de mérito de la Real Academia de San Fernando, que serían profesores de la escuela en cada una de sus especialidades. De este modo, contó con el arquitecto Ignacio Tomás, con el escultor Joaquín Arali y con el ya mencionado pintor Francisco Agustín, que además sería el encargado de dirigir la nueva institución (Rivas, 1986: 45). En la Escuela de Bellas Artes era una prioridad el dominio del dibujo, por lo que en las salas de estudio se utilizaban numerosas estampas realizadas por el propio Agustín, aunque también se recurría a otras colecciones de dibujos y grabados de autores célebres (Aranda, 1988: 39-46). Además, el prelado consiguió una importante biblioteca especializada para el centro, 
formada por 20 títulos entre 38 tomos y 63 cuadernos, adquiridos en su mayoría para la nueva escuela, aunque otros fondos procedían del Colegio de Santa Catalina, que pasaron a engrosar la biblioteca episcopal tras la expulsión de los jesuitas. Otros libros fueron depositados por el canónigo Cayetano Carrascal Delgado (Aranda, 1989: 10).

Los tres profesores, además de contar con una generosa remuneración por su labor en la escuela, contaban con atenciones y deferencias del obispo Caballero, que además les permitía aceptar encargos particulares, algunos propiciados por él mismo. Por ello, Ignacio Tomás fue arquitecto de la Fábrica y Obrería de la Iglesia Mayor, y Joaquín Arali compaginó su trabajo en la escuela con el honroso encargo de modelar las Fuentes del Tajo en los jardines de Aranjuez (Rey, 1989: 72). Francisco Agustín también contó con numerosos encargos a la vez que dirigía la escuela, muchos de ellos auspiciados por el mismo prelado, lo que explica que la mayor parte de sus obras se conserven en la capital cordobesa (Ossorio, 1975: 11). De hecho, el pintor logró un notable acomodo económico mediante la realización de pinturas religiosas para parroquias y monasterios (Rumeu, 2004: 39).

Francisco Agustín Grande nació en Barcelona, en 1753. Completó su formación en Madrid, en la Real Academia de San Fernando y fue discípulo de Antonio Rafael Mengs, llegando a ser uno de sus mejores imitadores. Pensionado por Carlos III en 1776, continuó en Roma sus estudios de pintura, donde además de conocer a los grandes maestros del Renacimiento y del Barroco, siguió aprendiendo del mismo Mengs, quien había regresado a Italia tras su estancia en Madrid. Así, pudo perfeccionar la técnica del dibujo, cuya gran corrección fue característica de todas sus obras (Jordán de Urríes, 1998). Durante esta etapa italiana, contó con el apoyo del cardenal D. Antonio Despuig y Dameto, quien le hizo muchos encargos, como su mismo retrato o los de Ramón y Juan Despuig y Zaforteza, conservados en la Casa del Conde de Montenegro, en Palma de Mallorca, junto a otros cuadros de temática religiosa. Cuando regresó a España, lo hizo con una gran reputación respaldada por su sólida formación clasicista, motivo por el que el obispo Antonio Caballero y Góngora le encargó la dirección de la referida Escuela de Bellas Artes (Ossorio, 1975: 11). La relación del pintor con el prelado fue muy estrecha, convirtiéndose en su patrono y llegando a bautizar en 1791 a su hijo Rafael (Valverde, 1962: 177).
En cuanto a su labor artística, Agustín se convirtió en el retratista de moda de la alta sociedad cordobesa, siendo considerado por Valverde Madrid como «el Goya cordobés». Realizó varios retratos del obispo Caballero, enviando uno de ellos a Priego de Córdoba, su localidad natal, y otro al Colegio de San Bartolomé y Santiago de Granada, del que había sido colegial. Para Córdoba realizó el magistral retrato del Colegio de la Asunción dedicado a un sobrino del prelado, el canónigo Pedro Segovia. Naturalmente, pintó otro para la Galería de Obispos del Palacio Episcopal, para la que realizó también retratos de los obispos Yusta Navarro y Garrido. De Caballero y Góngora hizo además un grabado del que se conservan dos muestras, una en el Gabinete de Estampas de la Biblioteca Nacional de Madrid y otra en la sacristía de la parroquia de Ntra. Sra. de la Asunción de Priego. Dentro de su amplia producción de retratos, se le ha atribuido el del Conde Ezpeleta en el Museo de Artillería de Segovia, destacando además el de D. Antonio Ruiz Castro Carrillo Rus, también sobrino del obispo, quien le acompañó junto a su esposa en su época de virrey en Nueva Granada. Este último lienzo se conserva en una colección particular de Priego (Valverde, 1962: 173). Otro personaje importante cordobés al que retrató fue el deán D. Francisco Fernández de Córdoba, Cueva y Ponce de León, su mecenas tras la muerte del obispo Caballero (Valverde, 1962: 174). Tampoco deben olvidarse los retratos del Sr. Ramírez de Verger y del primer duque de Rivas y su esposa, que en su tiempo estuvieron atribuidos a Agustín Esteve (Valverde, 1962: 176).

Respecto a la producción religiosa de Francisco Agustín, ha sido considerada más fría y académica. Entre estas obras destaca el cuadro de San Eulogio del Seminario de San Pelagio, en Córdoba, de grandes dimensiones e inspirado en el que Vicente Carducho realizó para la capilla catedralicia de la misma advocación. Para el Seminario realizó también un cuadro del Martirio de San Pelagio, y para las Escuelas Pías de primeras letras de Ntra. Sra. de la Concepción pintó una Inmaculada y un cuadro alegórico de su fundación con un San Ignacio. Uno de los encargos más importantes que tuvo fueron las pinturas para la iglesia del Colegio de Santa Victoria, encargadas por el mismo deán (Valverde, 1962: 174-175). Para el convento de los Mínimos realizó los lienzos de La Visita del Rey de Francia al Beato Gaspar Bono, conservado en la parroquia de San Nicolás de la Villa, y de San José, hoy en paradero desconocido. 


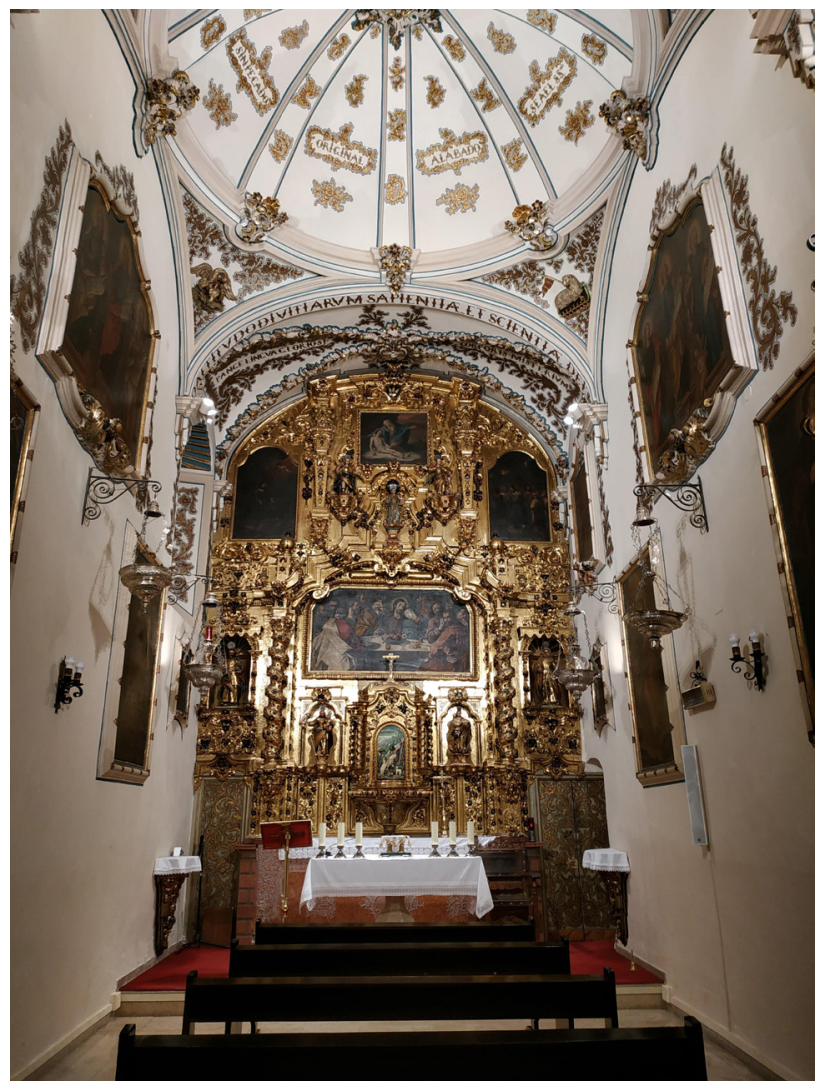

1. Capilla del Sagrario de la parroquia de San Miguel, Córdoba

Realizó también una Huida a Egipto para la iglesia de San Agustín, los cuadros de la vida de San Ignacio de la Real Colegiata de San Hipólito y de la sacristía del Salvador y Santo Domingo de Silos, y los lienzos de San Felipe Neri y la Sagrada Familia de la iglesia del convento de la Piedad. En 1797, Ana Fernández de Córdoba, pariente del mencionado deán, le encargó las pinturas de dos retablos laterales del desaparecido convento de religiosas de Santa María de Gracia. Finalmente, se deben mencionar las pinturas de San Ignacio de Loyola, San Francisco de Borja, Santa Teresa, San Rafael y la Virgen que según Valverde Madrid correspondían a un retablo neoclásico de la Catedral de Córdoba, en su momento atribuidas a Álvarez Torrado. En la Catedral de Jaén también cuenta con una obra, la representación de Santiago en la batalla de Clavijo (Valverde, 1962: 176).

A este conjunto de pinturas se suma ahora una nueva obra que había permanecido en el anonimato y que se localiza en el retablo de la capilla del Sagrario de la parroquia de San Miguel [1]. A partir de la consulta de las cuentas de la cofradía del Santísimo Sacramento de dicho templo correspondientes al período comprendido entre 1793 y 1798 , se ha podido documentar que, en el año 1795, el obispo Caballero y Góngora ordenó la retirada del lienzo que en ese momento remataba el retablo, una Santísima Trinidad que, según se apunta en el documento, se encontraba «defectuosa ${ }^{5}$. Dicha pintura fue realizada en 1762, durante la construcción y ornamentación de la capilla, siendo su artífice el pintor Pedro Ruiz Moreno, que recibió la cantidad de 200 reales por su hechura ${ }^{6}$. El pintor encargado de realizar el lienzo que vendría a sustituirla fue Francisco Agustín, que debió ser recomendado por el obispo a la cofradía, lo que confirmaría que el prelado proporcionaba encargos particulares a los tres profesores de la Escuela de Bellas Artes, y en especial, a su protegido. El encargo fue valorado en 220 reales de vellón, siendo el hermano mayor D. Pedro Díez de Casso quien firmó el recibo el 20 de noviembre de 1795. Sin embargo, en el nuevo lienzo no se repitió la temática de la Santísima Trinidad, sino que se representó una Piedad, o tal y como se indica en el documento Nuestra Señora en el acto de poner al Señor en el Sepulcro ${ }^{7}$ [2]. El hecho de que la pintura de la Santísima Trinidad se sustituyera por otra de un tema completamente diferente puede sugerir que su iconografía no debió parecerle adecuada al visitador. En el recibo firmado por Pedro Ruiz Moreno aparece descrita «con las tres partes iguales y distintas», por lo que pudo tratarse de una representación triándrica, es decir, tres personas con rostros idénticos pero distintos atributos, o incluso de una «Trinidad tricéfala» ${ }^{8}$. Por tanto, teniendo en cuenta que la antigüedad de la obra era de 33 años, no sería extraño que el motivo de la sustitución fuera más allá de su simple deterioro, pudiendo plantearse esta hipótesis junto con el probable interés del obispo Caballero en lograr un encargo de la cofradía para Agustín, a fin de introducirlo en el ámbito de las hermandades cordobesas y con ello para difundir la nueva estética.

La obra que se da a conocer es prácticamente idéntica a la que realizara el mismo pintor para los jesuitas cordobeses, que luego pasó a la Real Academia de San Fernando, y que es considerada como una de las mejores piezas de su museo $^{9}$ [3], con un estilo que fluctúa entre Murillo y Mengs (Alcolea, s.f.). La principal diferencia entre ambas es la variación del formato de los dos lienzos, horizontal en el 
2. Francisco Agustín Grande, La Piedad, 1795. Capilla del Sagrario de la parroquia de San Miguel, Córdoba

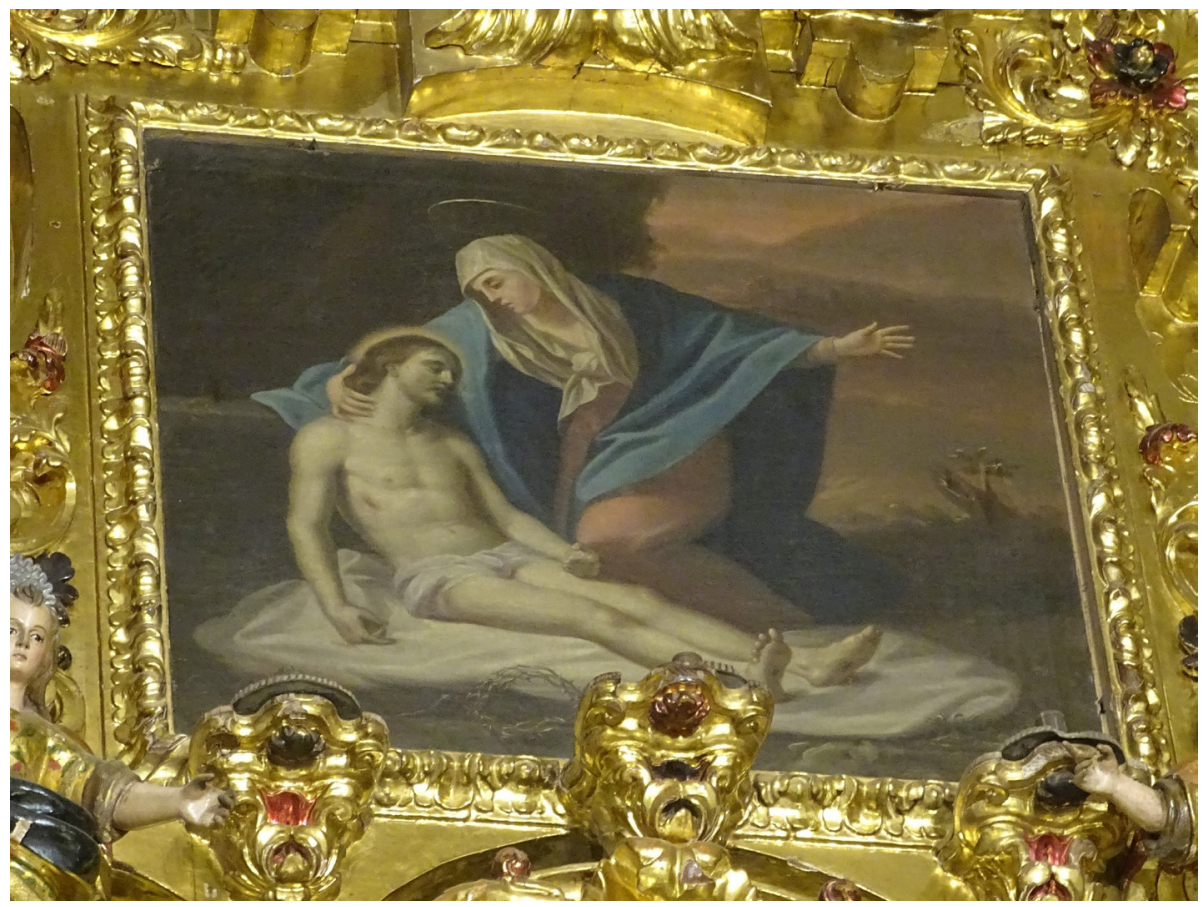

del Sagrario de San Miguel y vertical en el realizado para la Compañía de Jesús. Esta circunstancia obligó al pintor a representar dos fondos paisajísticos diferentes, aunque prácticamente con los mismos elementos. En ambos casos, tras la Virgen aparece una gran roca, y un paisaje similar ocupa el lado derecho, si bien en el lienzo de la capilla sacramental, que es más ancho, se representa además un pequeño arbusto. Otra diferencia es el nimbo de la Dolorosa, aquí representado corpóreo y tridimensional, mientras que en el cuadro de la Academia el pintor se limitó a introducir un pequeño halo sobre la cabeza de María. Por lo demás, la representación de la Virgen y Jesucristo es la misma, contándose incluso con algunos elementos de la Pasión en el suelo, tales como la corona de espinas y los clavos depositados sobre el sudario y la tierra en primer plano. Desde el punto de vista técnico, se corrobora la delicadeza del dibujo y la belleza en la composición propias de Francisco Agustín, dentro de la nueva tendencia academicista del momento. Se advierte un predominio del dibujo sobre el color, al igual que un tratamiento claro y difuso de la luz, delimitando los personajes y dotando de solemnidad al ambiente y a la escena en general. Los rostros se presentan dulcificados, carentes del dramatismo característico de las pinturas barrocas, y los

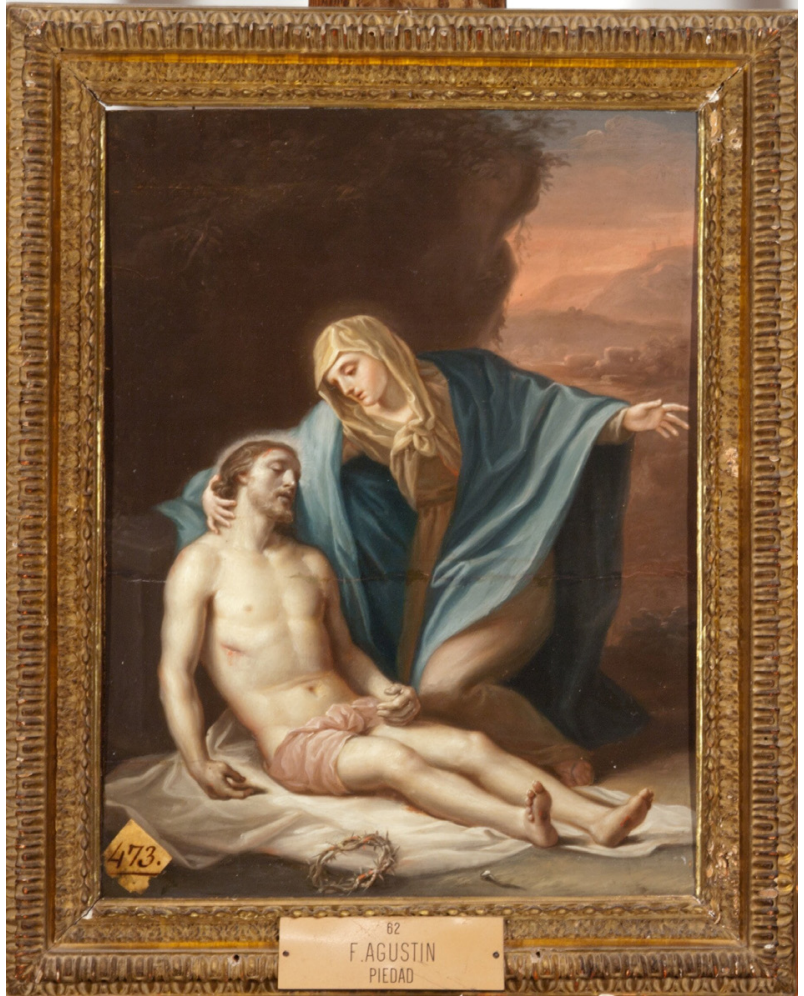

3. Francisco Agustín Grande, Piedad, segunda mitad del siglo XVIII. Real Academia de San Fernando, Madrid 
gestos son comedidos, también alejados de la teatralidad y el movimiento de la pintura precedente. Respecto a la composición, este lienzo presenta grandes similitudes con otras obras, como es el caso de La Piedad que realizó Antonio Van Dyck hacia 1629, conservada en el Museo del Prado (Díaz, 2012: 302-305). Dicho cuadro recoge el mismo fondo, de modo que a la izquierda aparece la gran roca, mientras que a la derecha se vislumbra un paisaje que es ocultado en parte por las figuras de María Magdalena y San Juan, que no aparecen en la obra de Agustín. También aparecen los elementos de la Pasión a los pies de Cristo, unos sobre el sudario y otros en el suelo. Lo mismo se contempla en la Lamentación sobre Cristo muerto del mismo autor flamenco, obra localizada en el Museo de Bellas Artes de Bilbao, realizada entre 1634 y 1640 (Díaz, 1990: 41-53). No obstante, existen además muchas similitudes con la obra de Mengs, su maestro. Es el caso de la Lamentación sobre Cristo muerto del Palacio Real de Madrid, pintado entre 1768 y 1769. De este lienzo se hicieron estampas como la conservada en el Museo del Prado, grabada por Giovanni Volpato en $1791^{10}$, pero también fue copiado en diversas ocasiones, destacando las obras anónimas del convento de las Capuchinas de Pinto y de la sacristía de la parroquia-santuario del Perpetuo Socorro de Madrid, la conservada en el Master and Fellows of St. John's College de Cambridge, la realizada por Francisco Lacoma y Sans del Museu de la Reial Acadèmia Catalana de Belles Artes de Sant Jordi o incluso la firmada por Agustín Robles en 1816 que se encuentra en la capilla del Cementerio de Ferrol, entre otras ${ }^{11}$. En la obra de Mengs, la figura de Cristo guarda una estrecha relación con el cuadro de Agustín, compartiendo incluso el tono blanquecino de su piel. También se advierte cierta relación en los atributos pasionistas, e incluso en la postura de María Magdalena, muy similar a la de la Virgen María en el lienzo del Sagrario de San Miguel.

Mengs realizó diversos dibujos preparatorios para esta obra, estando algunos íntimamente vinculados a la Piedad de Francisco Agustín. Uno de ellos es el estudio de la figura yacente de Cristo perteneciente al Museo del Prado, realizado en 1768 (AA.W., 2016: 130-134). Sin embargo, hay dos dibujos que se aproximan en mayor medida a la composición final del pintor catalán. Uno se encuentra en la colección de dibujos de los Uffizi, que contiene tres diseños alternativos donde destaca la figura de Cristo muerto, y so- bre todo la de María Magdalena, dibujada en una actitud y una postura muy parecida a la de la Virgen en la obra del sagrario de San Miguel. Lo mismo ocurre en el segundo boceto, procedente de la Colección Giuseppe Tealdo de Génova y conservado en Zurich, en la Colección Meissner. En este caso, de nuevo se advierte una composición muy semejante, estando la figura de la Magdalena mucho más cercana a la de Jesús, generándose una composición que recuerda en gran medida a la Piedad de la parroquia de San Miguel ${ }^{12}$. Por tanto, teniendo en cuenta que los discípulos de Mengs copiaban habitualmente sus obras y que incluso llegaban a conservar algún trabajo de su maestro (Jordán de Urríes 1998: 440), no sería extraño que Francisco Agustín entrara en contacto con los dibujos preparatorios de la Lamentación durante su formación en Roma, utilizándolos para constituir una versión simplificada de dicha escena de la pasión, valiéndose además de los elementos extraídos de las pinturas de Van Dyck.

Las mismas cuentas consultadas de la cofradía aportan otros detalles que ayudan a contextualizar la inclusión de esta obra en el retablo de la capilla sacramental. Así, el 24 de septiembre de 1795, aparece el encargo de dos ángeles lampareros al escultor Lorenzo Cano, recibiendo por su realización la cantidad de 1.900 reales de vellón ${ }^{13}$. Este escultor jienense, que trabajaba con su ayudante e hijo José, se afincó en Córdoba a finales del siglo XVIII, estableciendo su taller en las proximidades del Compás de San Francisco (Montes, 1986: 375), siendo junto a Juan Navarro, Diego de Morales y Fray Miguel Bellver uno de los escultores que hicieron triunfar en Córdoba el academicismo (Villar, 1982: 108-109). Dichos ángeles fueron realizados en un tamaño "de siete quartas de alto", y su estofado y dorado se incluyó en el precio mencionado ${ }^{14}$. Estas imágenes han desaparecido en la actualidad, desconociéndose su paradero, aunque sí debieron estar en tiempos de Teodomiro Ramírez de Arellano, pues apunta la presencia de unos ángeles de gran tamaño en la capilla (Ramírez, 2003: 8). También se ha podido descubrir que se llevaron a cabo unas obras de restauración en las bóvedas, las cuales se habían «descortezado» y desconchado, debiéndose acometer una renovación completa de las yeserías. El encargado de estas obras, realizadas en 1796 por la cantidad de 441 reales y 23 maravedíes, fue el maestro albañil Antonio José de Salas, de quien no se conocen noticias, mientras que José León se encargó de la pin- 
tura y redorado de los marcos de los lienzos de las paredes de la capilla, recibiendo 270 reales $^{15}$.

Estos datos sobre la capilla son muy ilustrativos respecto al momento artístico que vivía Córdoba a finales del siglo XVIII, comprobándose cómo las fórmulas academicistas acaban triunfando en la ciudad, auspiciadas por el obispo Caballero y Góngora a través de su Escuela de Bellas Artes. La realización del lienzo de la Piedad, junto al encargo de los dos ángeles lampareros, demuestran cómo a finales del siglo XVIIl ya se iban introduciendo obras academicistas en espacios concebidos originalmente en línea a un concepto y repertorio ornamental barroco. De hecho, la capilla sacramental de la parroquia de San Miguel había sido construida entre 1760 y 1762 (Serrano, 1970: 75-76), y decorada con lienzos, yeserías, esculturas y un retablo acorde con el arte barroco que se venía desarrollando en Córdoba desde el siglo XVII. No obstante, la cofradía comenzaría a «modernizar» el espacio sacramental con la inclusión de estas obras, a las que se sumaron otras pinturas del siglo XIX, caso de los lienzos de la Oración en el Huerto y del Prendimiento de Cristo situados en el segundo cuerpo del retablo y realizados por el pintor Diego Monroy (Ramírez, 2003: 8), autor también de una pintura en tabla del Salvador que le fue encargada el 24 de septiembre de 1833 para el mismo altar, hoy desaparecida ${ }^{16}$.

Con la muerte del prelado en 1796, la escuela cerraría sus puertas (Rey, 1923: 59), por lo que resultó un intento fallido. Respecto a Francisco Agustín, como ya se ha mencionado, tras el fallecimiento de Caballero estaría bajo el mecenazgo del deán Fernández de Córdoba. Un año antes, fue nombrado pintor de cámara real, y el 7 de octubre de 1799 fue admitido como profesor de la Real Academia de San Fernando, mientras que el 11 de diciembre del mismo año, la Junta de Barcelona le hizo director honorario de sus enseñanzas. Asimismo, en 1799 le encargaron como pintor de cámara de Carlos IV viajar a Sevilla para copiar cuadros de Murillo, de los cuales solo se conocen el Niño Jesús y San Juan, y la Virgen con Santa Isabel, ambos acabaron en la citada Colección de los Condes de Montenegro, en Palma (Valverde, 1962: 177). En esos mismos años se le encomendó la misión de copiar los cuadros de Murillo de la Iglesia de la Santa Caridad, para así trasladar los originales a las Colecciones Reales de Madrid, aunque se topó con una serie de dificultades que le planteó la cofradía. Precisamente, fue en este tiempo cuando, residiendo en Sevilla, realizó el conjunto de pinturas del retablo mayor de la parroquia de San Juan Bautista de las Cabezas de San Juan, pintadas entre 1798 y 1800 (Fernández, 2015: 24). Aunque Ossorio dató su muerte en Utrera en 1800, se ha demostrado que realmente falleció el 25 de octubre de 1801, no pudiendo concluir las copias de los lienzos de la Caridad (Alcolea, s.f.).

En definitiva, las nuevas tendencias academicistas fueron ganando terreno al Barroco en Córdoba desde mediados del siglo XVIII, estando a finales de siglo bastante implantadas. Con la llegada de Antonio Caballero y Góngora a la silla episcopal, la ciudad imitaría a otras como Valencia, Zaragoza, Sevilla, Salamanca, Barcelona, Cádiz, Burgos, Santiago o Granada con la creación de una Escuela o Academia de Bellas Artes (Rey, 1923: 57). La relación del obispo con sus tres profesores, y en especial con Francisco Agustín, hizo que proliferaran los encargos a dichos maestros. El cuadro de La Piedad del Sagrario de la parroquia de San Miguel constituye una muestra de los encargos que proporcionaba Caballero y Góngora a su protegido, y fue una nueva oportunidad para introducir una obra académica en un espacio barroco, sustituyendo la pintura primitiva que, desde entonces, está en paradero desconocido.

\section{Notas}

* Contratado FPI del proyecto Arquitecturas del poder en el Caribe y el Sudeste Asiático (1729-1764). (PGC2018-099323-B-I00).

1 Rivas, 1986: 26; Taylor, 1952.

2 Sobre la labor del Caballero y Góngora en Hispanoamérica véase Groot, 1890; Restrepo, 1934; Pérez, 1951 ; Restrepo, $1952 ;$ Restrepo, $1963 ;$ Mora, 1985.

3 Sobre esta cuestión, véase Martín, 1986; San Pío, 1992; Frías, 1994 y Collar, 1995.

4 Véase García, 2015

5 Archivo de la Parroquia de San Miguel, Córdoba (APSM, Córdoba), Cuentas de la cofradía del Santísimo Sacramento, s/f, 20 de noviembre de 1795.

6 Archivo General del Obispado de Córdoba (AGOC, Córdoba), Cuentas de la cofradía del Santísimo Sacramento de la parroquia de San Miguel, s/f, 28 de septiembre de 1762 .

7 Idem. 
8 AGOC, Cuentas de la cofradía del Santísimo Sacramento de la parroquia de San Miguel, s/f, 28 de septiembre de 1762.

9 Sobre esta obra en concreto, véase Pérez, 1964: 62 y Valverde, 1962: 390.

10 Sobre este grabado, véase Carrete, 1978: 28 y Vega, 1992: 223.

11 Acerca del lienzo del Palacio Real y sus copias, véase AA.W., 2016: 34-35; González, 1997: 197-212; Roettgen, 1993: 102-104 y 1999: 98-99; Morini, 1988; Águeda, 1980: 98.

12 Estos dibujos aparecen recogidos en Roettgen, 1999: 96-97.

13 APSM, Cuentas de la cofradía del Santísimo Sacramento, s/f, 24 de septiembre de 1795.

14 ld.

15 Ibid., 1 de enero de 1796.

16 Ibid., 24 de septiembre de 1833.

\section{Bibliografía}

AA. W. (2016), Carlos III: Majestad y Ornato en los Escenarios del Rey Ilustrado, Patrimonio Nacional, Servicio de Publicaciones, Madrid. ALCOLEA GIL, Santiago (s.f.), Francisco Agustín, Barcelona.

ARANDA DONCEL, Juan (1984), Historia de Córdoba. La época moderna (1517-1808), Monte de Piedad y Caja de Ahorros de Córdoba, Córdoba.

- (1988), «Un proyecto ilustrado en la Córdoba del siglo XVIII: La Escuela de Bellas Artes del Obispo Caballero y Góngora», Aphoteca, n. ${ }^{\circ}$ 6, pp. 33-49.

ARANDA DONCEL, Juan y NIETO CUMPLIDO, Manuel (1989), Antonio Caballero y Góngora: Arzobispo de Santa Fe de Bogotá, obispo de Córdoba, Córdoba.

CARRETE PARRONDO, Juan (1978), El grabado calcográfico en la España ilustrada: aproximación histórica, estampas de Manuel Salvador Carmona, repertorio de grabadores españoles del siglo XVIII, Club Urbis, Madrid.

COLLAR DEL CASTILLO, Paloma (1995), Catálogo del fondo documental José Celestino Mutis del Real Jardín Botánico, Consejo Superior de Investigaciones Científicas, Madrid.

DÍAZ PADRÓN, Matías (1990), «La Piedad (Lamentación sobre Cristo muerto) de Van Dyck en el Museo de Bellas Artes de Bilbao». Urtekaria 1989: asterlanak, albistak = anuario 1989: estudios, crónicas, Museo de Bellas Artes de Bilbao, Bilbao.

- (2012), Van Dyck en España, I, Prensa lbérica, Barcelona.

FERNÁNDEZ LÓPEZ, José, GONZÁLEZ ESTÉVEZ, Escardiel y RODRÍGUEZ SERRANO, Carmen (2015), «Adenda a un trabajo bien hecho», en ÁLVAREZ VILAR, Francisco Javier, Una catedral para un pueblo: Estudio histórico artístico de la parroquia de San Juan Bautista. Las Cabezas de San Juan (Sevilla), Diputación de Sevilla, Servicio de Archivo y Publicaciones, Sevilla.

FRÍAS, Marcelo (1994), Tras el Dorado vegetal: José Celestino Mutis y la Real Expedición Botánica del Nuevo Reino de Granada 1783-1808, Diputación Provincial, Sevilla.

GARCÍA SÁNCHEZ, Bárbara Yadira (2005), «La educación colonial en la Nueva Granada: entre lo doméstico y lo público», Revista de Historia de la Educación Latinoamericana, n. ${ }^{\circ} 7$, pp. 217-238.

GÓMEZ Y GÓMEZ, Tomás (1989), Vida y obra de Antonio Caballero y Góngora, Junta de Andalucía, Consejería de Cultura, Córdoba.

GROOT, José Manuel (1890), Historia Eclesiástica y Civil de la Nueva Granada, escrita sobre documentos auténticos, M. Rivas \& Cía, Bogotá.

JORDÁN DE URRÍES Y DE LA COLINA, Javier (1998), “Los últimos discípulos españoles de Mengs (Ramos, Agustín, Salesa, Napoli y Espinosa), en Actas del I Congreso Internacional de Pintura española del siglo XVIII, Museo del Grabado Español Contemporáneo, Madrid, pp. 435-450.

MARTíN FERRERO, Paz (1986), Simposium CCL Aniversario Nacimiento Joseph Celestino Mutis, Diputación Provincial, Cádiz.

MONTES RUIZ, Ramón (1986), «La escultura en Córdoba desde el Neoclasicismo a la actualidad», en Córdoba y su provincia, Gever, Sevilla, pp. 375-389. 
MORA MÉRIDA, José Luis (1985), «Ideario reformador de un cordobés ilustrado: El Arzobispo y Virrey don Antonio Caballero y Góngora», en TORRES RAMÍREZ, Bibiano y HERNÁNDEZ PALOMO, José J. (coords.), IV Jornadas de Andalucía y América, Consejo Superior de Investigaciones Científicas, Escuela de Estudios Hispanoamericanos, Sevilla, pp. 233-259.

ORTIZ JUÁREZ, Dionisio (1984), «Bosquejo histórico de la enseñanza de las artes plásticas en Córdoba durante el siglo XIX», Boletín de la Real Academia de Córdoba, de Ciencias, Bellas Letras y Nobles Artes, n. 106, Córdoba, pp. 21-35.

OSSORIO Y BERNARD, Manuel (1975), Galería biográfica de artistas españoles del siglo XIX, Manuel Ossorio y Bernard, Madrid.

PÉREZ DE AYALA, José Manuel (1951), Antonio Caballero y Góngora, Virrey y Arzobispo de Santa Fe (1723-1796), Imprenta Municipal, Bogotá.

PÉREZ SÁNCHEZ, Alfonso E. (1964), Real Academia de Bellas Artes de San Fernando. Inventario de pinturas, Real Academia de Bellas Artes de San Fernando, Madrid.

PITA PICO, Roger (2016), «Los avisos clasificados en la prensa de la ciudad de Bogotá: continuidades y rupturas de la colonia a la República», Revista Internacional de Historia de la Comunicación, n. ${ }^{\circ}$ 6, pp. 1-21.

RAMíREZ DE ARELLANO, Teodomiro (2003), Paseos por Córdoba, ó sean apuntes para su historia, Maxtor, Valladolid.

RESTREPO POSADA, José (1963), Arquidiócesis de Bogotá. Datos biográficos de sus Prelados, vol. 1, Academia Colombiana de Historia, Bogotá.

RESTREPO SÁENZ, José María (1952), Biografías de los mandatarios y ministros de la Real Audiencia (1671-1819), Academia Colombiana de Historia, Bogotá.

RESTREPO TIRADO, Ernesto (1934), Gobernantes del Nuevo Reino de Granada durante el siglo XVIII, Imprenta de la Universidad, Buenos Aires.

REY DÍAZ, José María (1923), "Don Antonio Caballero y Góngora», Boletín de la Real Academia de Córdoba de Ciencias, Bellas Letras y Nobles Artes, n. ${ }^{\circ}$ 6, pp. 53-76.

- (1989), "Una figura de relieve en la historia de Córdoba: D. Antonio Caballero y Góngora. Arzobispo-Virrey de Nueva Granada», en AA. W. El Obispo Caballero, un prieguense en América, M. Peláez del Rosal, Córdoba, pp. 13-101.

RIVAS CARMONA, Jesús (1986), «Notas para el Neoclásico cordobés», Imafronte, n. 2, pp. 25-55.

ROETTGEN, Steffi (1999), Anton Raphael Mengs 1728-1779. Das malerische und zeichnerische Werk, Band 1, Himer Verlag, Munich.

RUMEU DE ARMAS, Antonio (2004), «El pintor Agustín, autor del retrato goyesco de Mariano Luis de Urquijo, secretario de Estado del rey Carlos IV (1800)», en RUMEU DE ARMAS, Antonio, De arte y de historia, Real Academia de Historia, Madrid, pp. 33-46.

SAN PÍO ALADRÉN, M. a del Pilar (1992), Mutis and the Royal Botanical of the Nuevo Reyno de Granada, Villegas Editores, Bogotá.

SERRANO OVÍN, Vicente (1970), «La iglesia parroquial de San Miguel en Córdoba», Boletín de la Real Academia de Córdoba de Ciencias, Bellas Letras y Nobles Artes, n. ${ }^{\circ}$ 90, pp. 71-98.

VALVERDE MADRID, José (1962), «El cuadro de San Eulogio de Agustín Grande, en el Seminario de Córdoba», Boletín de la Real Academia de Córdoba de Ciencias, Bellas Letras y Nobles Artes, n. ${ }^{\circ}$ 84, pp. 169-183.

VEGA, Jesusa (1992), Museo del Prado: catálogo de estampas, Museo del Prado, Madrid.

VILLAR MOVELLÁN, Alberto (1982), «Barroco y Clasicismo en la Imaginería Cordobesa del Setecientos», Aphoteca, n. 2, pp. $101-138$. 